\title{
Notes and illustrations on Amicitia Emden species (Diptera, Muscidae, Coenosiinae)
}

\author{
Márcia S. Couri \\ Museu Nacional, Universidade Federal do Rio de Janeiro. Quinta da Boa Vista, São Cristóvão, 20940-040 Rio de Janeiro, Rio \\ de Janeiro, Brasil. Researcher of the CNPq.
}

\begin{abstract}
Amicitia Emden, 1940 is an Afrotropical genus of Coenosiinae (Diptera, Muscidae), with four known species described by EMDEN (1940): A. insignis, A. lucens, A. modesta and A. seclusa. All examined holotypes are deposited at "The Natural History Museum" (London, UK). Notes on the species and illustrations, especially of the terminalia are presented.
\end{abstract}

KEY WORDS. Afrotropical, morphology, terminalia.

The Afrotropical genus Amicitia Emden, 1940 includes four species described by Emden (1940): A. insignis, A. lucens, A. modesta and A. seclusa. The species are well characterized in the original descriptions, and can be easily segregated by the key provided by EMDEN (1940).

The type-material of the species, deposited at "The Natural History Museum" (London, UK), was examined in 1997 during the development of a post-doctoral project.

The scope of this paper is to illustrate some diagnostic characters of the species, give some morphological notes, descriptions, and illustrations of the terminalia.

\section{Amicitia Emden, 1940}

Amicitia Emden, 1940: 248-249 (description, key to species).

Type-species: Amicitia lucens Emden, 1940.

Diagnosis. (modified from EMDEN 1940 and characters of terminalia added). Length: 3.6-5.5 mm. Frons strongly protruding in profile at base of antenna (not so much in A. modesta), with two pairs of reclinate frontal setae (Fig. 1); dorsocentrals $2: 3$, the first pre-sutural shorter than the second and sometimes absent; apical scutellar bristles very strong and postscutellum high, convex (Fig. 2); katepisternals 1:1:1 or almost in this disposition (Fig. 3), sometimes the anterior one absent or very short; fore and mid tibiae with a posterodorsal submedian seta; hind tibia with two anterodorsal seta, one anteroventral and one posterodorsal in males or two in females and some males; costal vein without spine, reaching apex of $\mathrm{M}$; lower calypter elongated, much longer than the upper one (Fig. 4); abdomen of male cylindrical (Figs 5, 6); abdomen of female with parallel margins. Sternite 5 with two apical lobes (Fig. 7). Sternite 6 symetric (Fig. 8). Hypandrium plate-like, not tubular.
Discussion: According to EMDEN (1940), Amicitia species would run to Phyllogaster Stein, det. (junior synonym for Pachyceramyia Albuquerque, det.) in SÉGUY (1937) key, differing from this for the presence of two pairs of reclinate frontal setae. In Couri \& PONT (1999) key to the world Coenosiini genera, Amicitia runs to number 9 and is segregated by the projected profrons, antennal insertion above mid-level of eye; anterior postsutural dorsocentral setae hair-like in some species; ocellar triangle short and 1 pair of postsutural intraalar seta. In Couri \& PONT (2000) cladistics analysis, Amicitia is part of the Lispocephala group, defined by the following synapomorphies: presence of a posteroventral apical seta on the hind tibia, presence of both arms on male sternite and the short female ovipositor. All representants of this group have two pairs of reclinate setae.

\section{A. Iucens Emden, 1940 \\ Figs $1-15$}

Amicitia lucens Emden, 1940: 252-254 (description of male and female, fig. 82 . hind tibia of male)

Holotype male. Holotype male [round label with red margin]. Kanaba,/7,300-7,800 ft./F. W. Edwards. UGANDA:/ Kigesi Dist./ xi.1934./ B.M.E. Afr. Exp./B.M. 1935-203/ Amicitia lucens sp. n./ van Emden det. 1939 (abdomen dissected).

Diagnosis. Arista hardly longer than flagellum; dorsocentral post-suturals only one or two fairly strong, the first posterior pair and the two pre-sutural ones very weak; mesonotum with vittae black and shinning; lateral scutellar absent; apical long and strong; hind tibia in male on posterodorsal surface with two longitudinal rows of very long setae, some of them curled at apex (Fig. 9), hind tibia in female without these setae, and with two anterodorsal, two 

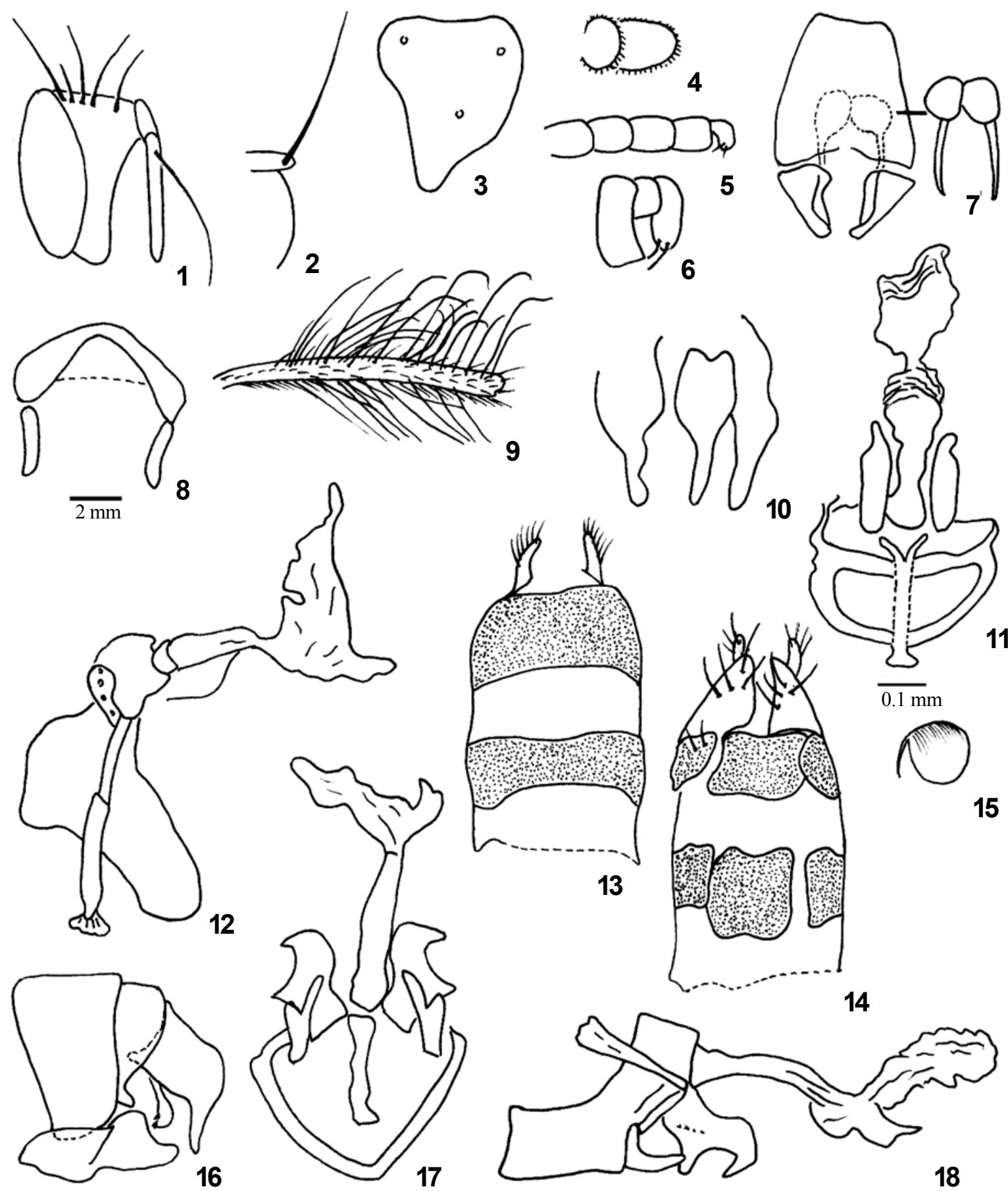

10

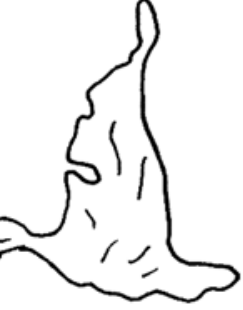


posterodorsal and one or two anteroventral setae. Sternite 5 quadrangular, with triangular lobes (Fig. 7).

Terminalia. Cercal plate reduced (Fig. 10); phallic complex as in figures 11 and 12 .

Female ovipositor. Short, with large tergites and sternites, epiproct not visible, hypoproct divided longitudinally into two parts (Figs 13 and 14). Spermatheca round, smooth (Fig. $15)$.

Examined material: Holotype, one paratype male and four paratypes female - all with same labels as holotype.

Comments. Couplets five and six of EMDEN (1940) key distinguish $A$. lucens and $A$. insiginis by the length of the third joint of arista, lateral scutellar setae and legs chaetotaxy.

\section{A. insignis Emden, 1940}

Amicitia insignis Emden, 1940: 254-255 (description of male).

Holotype male. Holotype male [round label with red margin]. Mt. Sabinio/ 8,000 ft/ UGANDA /Kigesi Dist./ xi.1934./ F.W.E./ Ruwenz./ Exp.II. Amicitia insignis sp. n./ van Emden det. 1939.

Diagnosis. Arista more than twice as long as flagellum, bare on ventral surface; dorsocentral post-suturals only one or two fairly strong, the first posterior pair and the two pre-sutural ones very weak; mesonotum with vittae black and shinning; scutellum with a pair of small lateral sub-basal hairs, a pair of lateral hairs and long apical setae; the lateral scutellars are hair-like; anterior katepisternal very weak (original description mentions only two katepisternal present); fore pre-tarsus distinctly long; hind tibia with two posterodorsals, one anterodorsal and two small anteroventral, apical half of ventral surface with 9 long and strong setae, posterior and posterodorsal surfaces with fine erect setae, some of them curled at apex.

Examined material: Holotype male.

Comments. The only known exemplar is the holotype male. See comment in A. lucens.

\section{A. modesta Emden, 1940}

Amicitia modesta Emden, 1940: 259-251 (description of male and female).

Holotype male. Holotype male [round label with red margin]. Namwanba Valley/ 8,300 ft/ UGANDA /xi.1934./ F.W.E./ Ruwenz./ Exp.II. Amicitia modesta sp. n./ van Emden det. 1939

Diagnosis. dorsocentral post-suturals 3 strong; mesonotum with vittae brown pollinose; lateral scutellar setae small, but distinct; katepisternal 3 strong; hind tibia of male and female not hairy, only with 1 or 2 small posterodorsals, a small and a strong anterodorsal and a rather short anteroventral; general coloration of fore coxa and all femora yellow.
Terminalia not dissected.

Examined material: Holotype male and two paratypes males, one with the same label as holotype and the other: Mt. Sabinio/ 8,000 ft/ UGANDA /Kigesi Dist./ xi.1934./ F.W.E./ Ruwenz./ Exp.II. Amicitia modesta sp. n./ van Emden det. 1939.

Comments. Only male examined. In EMDEN (1940) key, this species approaches $A$. seclusa, from which can be distinguished by the general colour of fore coxa and all femora and by the shape of the anterior paramere - strongly curved, clawshaped in $A$. modesta and slightly curved, spine-shaped in $A$. seclusa.

\section{A. seclusa Emden, 1940 Figs 16-18}

Amicitia seclusa Emden 1940:251-252 (description of male).

Holotype male. Holotype male [round label with red margin]. Mt. Sabinio/ 8,000 ft/ UGANDA /Kigesi Dist./ xi.1934/ F.W.E./ Ruwenz./ Exp.II. Amicitia seclusa sp. n./ van Emden det. 1939.

Diagnosis. dorsocentral post-suturals 3 strong; mesonotum with vittae brown pollinose; lateral scutellar setae small, but distinct; katepisternal 3; hind tibia of male an d female not hairy, with one or two posterodorsals, a small and a strong anterodorsal and a strong anteroventral; general colour of fore coxa and all femora black. Apex of abdomen as in figure 16.

Terminalia. Aedeagus complex as in figures 17 and 18 .

Examined material: Holotype male and two paratypes males from: Kanaba/ 7,300-7,800 ft/ UGANDA /xi.1934./ F.W.E./ Ruwenz./ Exp.II. Amicitia seclusa sp. n./ van Emden det. 1939.

Comments. Female unknown. See comment in $A$. modesta.

\section{ACKNOWLEDGMENTS}

The author is grateful to the colleagues at "The Natural History Museum", London for the facilities to exam this material.

\section{REFERENCES}

EMden, F.I. van. 1940. Ruwenzori Expedition. London, British Museum (Natural History), vol. 2, no. 4, p. 91-255.

Couri, M.S. \& A.C. Pont. 1999. Key to the world Coenosiini (Diptera, Muscidae, Coenosiinae). Studia dipterologica, Halle (Salle), 6 (1): 93-102.

. 2000. Cladistic analysis on Coenosiini (Diptera, Muscidae, Coenosiinae). Systematic Entomology, London, 25: 373-392.

SÉGuY, E. 1937. Diptera. Fam. Muscidae. In: P. Wytsman (Ed.). Genera Insectorum 205, 604p, Bruxelles.

Received in 06.VI.2003; accepted in 27.X.2003. 